\title{
Comparative Study between Lidocaine 2\% and Dexamethasone Local Wound Infiltration Effect on Postoperative Pain Post Mastectomy: A Randomized Controlled Study
}

\author{
Hussein 0. Soliman \\ National Cancer Institute, Cairo, Egypt \\ Email: soliman@daad-alumni.de
}

How to cite this paper: Soliman, H.O. (2018) Comparative Study between Lidocaine $2 \%$ and Dexamethasone Local Wound Infiltration Effect on Postoperative Pain Post Mastectomy: A Randomized Controlled Study. Advances in Breast Cancer Research, 7, 243-249.

https://doi.org/10.4236/abcr.2018.74015

Received: August 11, 2018

Accepted: August 28, 2018

Published: August 31, 2018

Copyright $\odot 2018$ by author and Scientific Research Publishing Inc. This work is licensed under the Creative Commons Attribution International License (CC BY 4.0).

http://creativecommons.org/licenses/by/4.0/

(c) (i) Open Access

\begin{abstract}
Objective: To compare the efficacy and safety of Lidocaine $2 \%$ versus Dexamethasone injected locally in mastectomy wound as pain relieving agents. Materials \& Methods: A randomized single-blinded study in which 50 patients candidate for Mastectomy were included. Participants were equally randomized into two groups; Group A, in which patients received $10 \mathrm{ml} \mathrm{Li}$ docaine $2 \%$ and Group B, in which patients received $16 \mathrm{~mL}$ Dexamethasone. In both groups, the drugs were given via local infiltration in the subcutaneous layer of the Mastectomy wound immediately after skin closure. Pain control was assessed post-operatively in the first 24 hours using the visual analogue scale (VAS) in addition the need for additional analgesia was recorded. Results: There was a statistically significant lower VAS score in group A (Lidocaine group) when compared to those in group B (Dexamethasone group) 1 h, $6 \mathrm{~h}, 12 \mathrm{~h}$ postoperatively with no significance $24 \mathrm{~h}$ postoperatively (36\% vs $64 \% 1 \mathrm{~h}, 28 \%$ vs $64 \% 6 \mathrm{~h}, 30 \%$ vs $72 \% 12 \mathrm{~h}$ and, $80 \%$ vs $60 \% 24 \mathrm{~h}$ ). This statistical significance was evident throughout the post-operative hours $(1 \mathrm{~h}, 6 \mathrm{~h}$, $12 \mathrm{~h}$ ). Though local Lidocaine caused marked improvement of pain in bigger number of patients in group A than group B, yet it showed no statistical significance $24 \mathrm{~h}$ post-mastectomy. Furthermore, the number of participants that needed additional doses of analgesia lower in group A (48\% vs 56\%) in comparison to group B, but still showed no statistical significance. Conclusion: Local injection of Lidocaine 2\% in Mastectomy wounds, has an upper hand in reducing the post-operative pain and showed a lesser need for post-operative analgesia when compared to local Dexamethasone injection.
\end{abstract}

\section{Keywords}

Post-Mastectomy Pain, Lidocaine, Dexamethasone 


\section{Introduction}

Many modalities of pain control post mastectomy have been used and tried: opioids and thoracic paravertebral blocks by local anesthetic agents [1]. However opioids have some undesirable side effects as severe nausea and vomiting together with urinary retention and constipation and delayed bowel activity [2]. Usually there's a limitation for thoracic paravertebral block due to lack of the skillful personnel to carry out the procedure. Also transthoracic block carries iatrogenic risks as nerve injury, bleeding and pneumothorax [3].

Many studies have illustrated the effect of intraoperative or postoperative effect of intravenous Lidocaine infusions for postoperative pain control in mastectomy patients [4].

Tissue damage and the inflammatory process at wound site induce pain which can be reversed by corticosteroids (Dexamethasone) [5]. On the other hand, Lidocaine blocks the sodium channels in the nerve axons that transmit the pain signals at wound site with an extended effect [6]. The current study aimed to compare between the efficacy and safety of Lidocaine $2 \%$ and Dexamethasone injected locally in mastectomy wounds for pain relief.

\section{Materials and Methods}

This study is a single-blinded randomized one in which 50 female patients candidate for mastectomy were included. Patients were recruited from the National cancer institute outpatient clinic department (faculty of medicine-Cairo university) in the duration between January 2017 and January 2018. The study was approved by the Hospital Ethical Committee. All participants provided an informed written consent after explaining the aim of the study, the procedure and the potential hazards.

Inclusion criteria included healthy females, aged from 30 to 60 years old and weighed from 50 - $90 \mathrm{~kg}$ with no history of previous breast diseases or breast surgeries. Patients with prior breast surgeries were excluded from the study. Patients who had allergies to either Lidocaine or Dexamethasone were also excluded (all patients underwent hypersensitivity test for both drugs before the mastectomy procedure). The participants were equally randomized into two groups; group $\mathrm{A}$; in which patients received $10 \mathrm{ml}$ Lidocaine $2 \%$ and group $\mathrm{B}$; in which patients received $16 \mathrm{~mL}$ Dexamethasone. In both groups, the drugs were given via local infiltration in the subcutaneous layer of the Mastectomy wound immediately after skin closure. Only the participants were masked to the group allocation. Randomization was done by a computer driven number sequence and the patient picks an envelope.

All participants underwent the following:

Full history taking, complete physical examination (general and local) and laboratory investigations (Complete blood count-Liver enzymes \& kidney function-random blood sugar-coagulation profile). 
All cases were diagnosed via local examination complemented by breast ultrasound, mammogram (Senohraphe Essential, GE) with or without MRI with contrast (MR750W 3.0 T, GE). All designed patients allocated were stage 1 or 2 breast carcinoma. All patients underwent Mastectomy under general anesthesia to assess the pain properly immediately after surgery (general anesthesia was induced using thiopental $5 \mathrm{mg} / \mathrm{kg}$ and succinylcholine $1 \mathrm{mg} / \mathrm{kg}$ with ventilation of $100 \% \mathrm{O}_{2}$ ).

All mastectomies were done by surgery residents, assistant lecturers and lecturers under the supervision of senior staff oncosurgeons. Mastectomy procedures varied between simple mastectomy (Simple mastectomy (or "total mastectomy"): In this procedure, the entire breast tissue is removed, but axillary contents are undisturbed or modified radical mastectomy: The entire breast tissue is removed along with the axillary contents (fatty tissue and lymph nodes).

After skin closure, the subcutaneous tissue was infiltrated in the upper and lower layers with lidocaine $2 \%$ titrated to $10 \mathrm{ml}$ distilled water (Debocaine $2 \%$ Pharma SAE, Cairo, Egypt) for group A, while in group B, the subcutaneous tissue was infiltrated with Dexamethasone ( $8 \mathrm{mg} / 2 \mathrm{ml}$, AMRIYA, Cairo, Egypt). Post-operative analgesia in the form of intravenous Paracetamol vial (Perfalgan, $10 \mathrm{mg} / \mathrm{ml} /$ Bristol-Myers-Squibb) every 8 hours, and Voltaren $(75 \mathrm{ml}$ ) (Novarrtis) intramuscular injection every 8 hours alternatively for the first 48 hours. Pain control was assessed post-operatively in the first 24 hours using the visual analogue scale (VAS). Patients were instructed to report pain using paper of VAS that had a line from 0 (no pain) to $10 \mathrm{~cm}$ (worst pain). Pain assessment was done after 1, 6, 12 and 24 hours postoperatively. Furthermore, the need for additional analgesia was recorded. Additional rescue dose of analgesic in the form of $50 \mathrm{mg}$ pethidine was given intramuscular according to VAS score as shown in Table 1. All patients were instructed to contact the doctors immediately if any adverse effects had occurred (e.g., hypersensitivity reaction, healing problems).

Primary outcome included comparing the efficacy of both drugs in controlling postoperative pain (via comparing VAS score in both groups) while secondary outcome included comparing the percentage of patients required additional doses of analgesia and the occurrence of adverse effects.

Statistical methods:

Data were coded and entered using the statistical package SPSS version 25. Data was summarized using mean and standard deviation for quantitative variables and frequencies (number of cases) and relative frequencies (percentages) for categorical variables. Comparisons between groups were done using unpaired $t$ test (Chan, 2003a). For comparing categorical data, Chi square (c2) test was performed. Exact test was used instead when the expected frequency is less than 5 (Chan, 2003b). P-values less than 0.05 were considered as statistically significant.

\section{Results}

The results of the current study showed no statistical difference between both groups as regarding the age or weight (Table 2). 
There was a statistically significant lower VAS score in group A when compared to those in group B $1 \mathrm{~h}, 6 \mathrm{~h}, 12 \mathrm{~h}$ postoperatively with no significance $24 \mathrm{~h}$ postoperatively (36\% vs $64 \% 1 \mathrm{~h}, 28 \%$ vs $64 \% 6 \mathrm{~h}, 30 \%$ vs $72 \% 12 \mathrm{~h}$ and, $80 \%$ vs $60 \% 24 \mathrm{~h}$ ) (Table 3). This statistical significance was evident throughout the post-operative hours ( $1 \mathrm{~h}, 6 \mathrm{~h}, 12 \mathrm{~h}$ ) (Table 3 ). Though local Lidocaine caused marked improvement of pain in bigger number of patients in group $A$ than group B, yet it showed no statistical significance $24 \mathrm{~h}$ post-mastectomy.

Furthermore, the number of participants that needed additional doses of analgesia was lower in group A (48\% vs 56\%) in comparison to group B, but still showed no statistical significance (Table 3 ). There were no reports of any adverse effect up to 1 week following surgery.

Table 1. Doses of pethidine used according to VAS pain score.

\begin{tabular}{cc}
\hline VAS & Pethidine \\
\hline$<4$ & No pethidine \\
$4-6$ & $25 \mathrm{mg} \mathrm{P}$ \\
$6-8$ & $30 \mathrm{mg} \mathrm{P}$ \\
$>5$ & $40 \mathrm{mg} \mathrm{P}$ \\
\hline
\end{tabular}

Table 2. Patients' characteristics.

\begin{tabular}{cccccc}
\hline & \multicolumn{2}{c}{ Group A } & \multicolumn{2}{c}{ Group B } & P value \\
\hline & Mean & $\begin{array}{c}\text { Standard } \\
\text { Deviation }\end{array}$ & Mean & $\begin{array}{c}\text { Standard } \\
\text { Deviation }\end{array}$ & \\
\hline Age & 57.24 & 17.81 & 55.00 & 16.50 & 0.647 \\
Weight & 72.48 & 11.75 & 72.96 & 12.29 & 0.888 \\
\hline
\end{tabular}

Table 3. Pain assessment (VAS score: 0 - 10) and need for additional analgesia.

\begin{tabular}{|c|c|c|c|c|c|c|}
\hline & & \multicolumn{2}{|c|}{ Group A } & \multicolumn{2}{|c|}{ Group B } & \multirow[t]{2}{*}{$P$ value } \\
\hline & & Count & $\%$ & Count & $\%$ & \\
\hline \multirow[t]{2}{*}{ Pain $1 \mathrm{~h}$} & $\mathrm{Y}$ & 9 & $36.0 \%$ & 16 & $64.0 \%$ & 0.048 \\
\hline & $\mathbf{N}$ & 16 & $64.0 \%$ & 9 & $36.0 \%$ & \\
\hline \multirow[t]{2}{*}{ Pain $6 \mathrm{~h}$} & $\mathrm{Y}$ & 7 & $28.0 \%$ & 16 & $64.0 \%$ & 0.011 \\
\hline & $\mathbf{N}$ & 18 & $72.0 \%$ & 9 & $36.0 \%$ & \\
\hline \multirow[t]{2}{*}{ Pain $12 \mathrm{~h}$} & $\mathrm{Y}$ & 5 & $20.0 \%$ & 18 & $72.0 \%$ & $<0.001$ \\
\hline & $\mathbf{N}$ & 20 & $80.0 \%$ & 7 & $28.0 \%$ & \\
\hline \multirow[t]{2}{*}{ Pain $24 \mathrm{~h}$} & $\mathrm{Y}$ & 20 & $80.0 \%$ & 15 & $60.0 \%$ & 0.123 \\
\hline & $\mathbf{N}$ & 5 & $20.0 \%$ & 10 & $40.0 \%$ & \\
\hline \multirow[t]{2}{*}{ Additional analgesia } & $\mathrm{Y}$ & 12 & $48.0 \%$ & 14 & $56.0 \%$ & 0.571 \\
\hline & $\mathbf{N}$ & 13 & $52.0 \%$ & 11 & $44.0 \%$ & \\
\hline
\end{tabular}




\section{Discussion}

Our study demonstrated that local lidocaine $2 \%$ infiltration caused marked improvement of pain in the postoperative period, but wasn't extended enough to 24 hours; post operatively when compared to dexamethasone local infiltration as they both showed similar effect (lesser pain scores on the VAS score and lesser need for rescue analgesic). And they had a similar effect for the need of extra dose of analgesia.

To the best of our knowledge, this is the sole study that compares the efficiency of local lidocaine $2 \%$ versus local dexamethasone infiltration in mastectomy wounds post-operatively and the only study performed for the patients undergoing Mastectomy under general anesthesia.

MacGregor et al. stated that local Lidocaine 2\% not only has a local neuronal blockade effect but also, an anti-inflammatory effect proven by the extended time of pain relief up to 24 hours [7]. Some stated that Local lidocaine $2 \%$ may interfere with the healing or has significant haemodynamic changes, or significant hypersensitivity, none of these occurred. Cesarean section scars have also been subjected to many studies comparing intravenous and local Lidocaine subcutaneous injection with a dramatic relief of pain postoperatively [8]. Other studies also suggested that the preoperative use of Lidocaine subcutaneous infiltration extended the pain relief to only 6 hours postoperatively and reduces the need for postoperative opioid [9].

Dexamethasone is a potent long lasting anti-inflammatory drug. The activation of inflammatory response has an important value in the production of all types of cytokines that reduce the patient's tolerance to pain, and a vicious cycle is initiated to cause more inflammatory response [10]. Bisgaard et al. assessed the role of preoperative injection of local dexamethasone in patients undergoing laparoscopic cholecystectomy; which suggested a marked analgesic and anti-inflammatory role for dexamethasone by reducing the prion inflammatory factors and cytokines production by producing local lipocortin 1 that has a potential anti-inflammatory mediating effect [11]. A similar study examined the effect of intravenous Lidocaine infusion given to patients elected for mastectomy before the induction of general anaesthesia and stopped one hour after the procedure, showing marked improvement in pain control over 24 hours [12]. Others compared the effect of thoracic paravertebral block versus local anaesthesia before general anaesthesia showing actual relief of pain postoperatively and extended to years later equally [13].

The main limitation to this study included the use of (VAS) scoring system which is a subjective way for assessment of pain. We excluded patients with prior breast diseases or breast surgeries to exclude the effect of fibrosis on the extent of pain. Moreover, the impact of dexamethasone \& lidocaine was not assessed in the presence of regional analgesia; thoracic paravertebral block which warrants further investigation in the future. In conclusion, local injection of 
Lidocaine 2\%, in Mastectomy wounds, has an upper hand in reducing the post-operative pain and showed a lesser need for post-operative analgesia when compared to local Dexamethasone injection.

\section{Conflicts of Interest}

The authors have no conflicts of interest.

\section{References}

[1] Trescot, A.M., Datta, S., Lee, M. and Hansen, H. (2008) Opioid Pharmacology. Pain Physician, 11, S133-S153.

[2] Schnabel, A., Reichl, S.U., Kranke, P., Pogatzki-Zahn, E.M. and Zahn, P.K. (2010) Efficacy and Safety of Paravertebral Blocks in Breast Surgery: A Meta-Analysis of Randomized Controlled Trials. British Journal of Anaesthesia, 105, 842-852.

https://doi.org/10.1093/bja/aeq265

[3] Naja, Z. and Lonnqvist, P.A. (2001) Somatic Paravertebral Nerve Blockade. Incidence of Failed Block and Complications. Anaesthesia, 56, 1184-1188. https://doi.org/10.1046/j.1365-2044.2001.02084-2.x

[4] Koppert, W., Weigand, M., Neumann, F., et al. (2004) Perioperative Intravenous Lidocaine Has Preventive Effects on Postoperative Pain and Morphine Consumption after Major Abdominal Surgery. Anesthesia \& Analgesia, 98, 1050-1055. https://doi.org/10.1213/01.ANE.0000104582.71710.EE

[5] Khalaj, A.R., Miri, S.R., Po Lashkari, M. and Mohammadi, A. (2013) Prophylactic Antiemetic Effect of Dexamethazone and Metocloporamide on Nausea and Vomiting Induced by Laparoscopic Cholecystectomy: A Randomized Double Blind, Placebo Controlled Trial. Journal of Minimally Invasive Surgical Sciences, 2, 18-22.

[6] Soleimanpour, H., Hassanzadeh, K., Vaezi, H., Golzari, S.E., et al. (2012) Effectiveness of Intravenous Lidocaine versus Intravenous Morphine for Patients with Renal Colic in the Emergency Department. BNC Urology, 12, 13.

[7] MacGregor, P.R., Thorner, R.E. and Wright, D.M. (1980) Lidocaine Inhibits Granulocyte Adherence and Prevents Granulocyte Delivery to Inflammatory Sites. Blood, 56, 203-209.

[8] Mansour, M.G., Rahman, S. and Jafarabai, M. (2015) local Lidocaine 2\% in Postoperative Pain Management in Caserean Delivery. Journal of Family and Reproductive Health, 9, 19-21.

[9] Sekhavat, L. and Behdad, S. (2011) Preoperative Analgesia with Local Lidocaine for Cesarean Delivery Pain Relief. The Journal of Maternal-Fetal and Neonatal Medicine, 24, 891-893. https://doi.org/10.3109/14767058.2010.537410

[10] Walash, D.A., Mapp, P.I. and Kelly, S. (2015) Calcitonin Gene-Related Peptide in the Joint: Contributions to Pain and Inflammation. British Journal of Clinical Pharmacology, 80, 965-978.

[11] Bisgaard, T., Klarskov, B., Kehlet, H. and Rosenberg, J. (2003) Preoperative Dexamethasone Improves Surgical Outcome after Laparoscopic Cholecystectomy: A Randomized Double-Blind Placebo-Controlled Trial. Annals of Surgery, 238, 651-660. https://doi.org/10.1097/01.sla.0000094390.82352.cb

[12] Grigoras, A., Lee, P., Sattar, F. and Shorten, G. (2012) Perioperative Intravenous Lidocaine Decreases the Incidence of Persistent Pain after Breast Surgery. The Clinical Journal of Pain, 28, 567-572. 
[13] Chiu, M., Bryson, G.L., Lui, A., Watters, J.M., Taljaard, M. and Nathan, H.J. (2014) Reducing Persistent Postoperative Pain and Disability 1 Year after Breast Cancer Surgery: A Randomized, Controlled Trial Comparing Thoracic Paravertebral Block to Local Anaesthesia. Annals of Surgical Oncology, 21, 795-801.

https://doi.org/10.1245/s10434-013-3334-6 